\title{
De Portugal à África a Macau: exclusões, inclusões
}

\author{
Monica Simas
}

Universidade de São Paulo

\begin{abstract}
RESUMO: ESTE TRABALHO PRETENDE REFLETIR SOBRE A PRESENÇA PORTUGUESA NO ORIENTE, MAIS ESPECIFICAMENTE, SOBRE DESLOCAMENTOS DE ESCRITORES PORTUGUESES QUE ENVOLVEM AS ROTAS DA ÁFRICA A MACAU. DESSA FORMA, BUSCAREMOS CONTRIBUIR PARA UMA DISCUSSÃO QUE GIRA EM TORNO DE DETERMINAÇÕES COMPLEXAS DOS AGENCIAMENTOS LITERÁRIOS. O DESENRAIZAMENTO DE ESCRITORES DE LÍNGUA PORTUGUESA DISPONIBILIZA EFETIVAS INTERAÇÕES QUE PRECISAM SER REGISTRADAS. EMBORA SEJA DIFÍCIL IDENTIFICAR E CARACTERIZAR A LITERATURA DE MACAU, HOUVE, NO PERÍODO DE TRANSIÇÃO (1987-1999), A PUBLICAÇÃO DE LIVROS IMPORTANTES DE ESCRITORES QUE PASSARAM PELAS ROTAS DE PORTUGAL À ÁFRICA A MACAU.
\end{abstract}

ABSTRACT: THIS PAPER INTENDS TO REFLECT ABOUT THE PORTUGUESE PRESENCE IN THE ORIENT, MORE SPECIFICALLY, ABOUT THE DISPLACEMENTS OF PORTUGUESE WRITERS THAT INVOLVES THE ROUTES FROM AFRICA TO MACAO. IN THIS WAY, WE WILL TRY TO CONTRIBUTE TO A DISCUSSION THAT TURNS AROUND COMPLEX LIMITS OF LITERARY AGENCY ACTIVITIES. THE UPROOT OF WRITERS WHO WRITE IN PORTUGUESE LANGUAGE DOES AVAILABLE EFFECTIVE INTERACTIONS THAT NEED TO BE RECORDED. ALTHOUGH IT IS DIFFICULT TO IDENTIFY AND TO CHARACTERIZE MACAO'S LITERATURE, THERE WAS, IN THE TRANSITION PERIOD (1987-1999), THE PUBLICATION OF IMPORTANT BOOKS FROM WRITERS WHO PASSED BY THE ROUTES OF PORTUGAL TO AFRICA TO MACAO.

PALAVRAS-CHAVE: LITERATURA DE MACAU - LITERATURA E DIÁSPORA - LITERATURAS DE LÍNGUA PORTUGUESA

KEY-WORDS: MACAO'S LITERATURE - LITERATURE AND DIASPORA - LITERATURE OF PORTUGUESE LANGUAGE 
literatura em língua portuguesa tem apresentado, ao longo do tempo, inumeráveis rotas de significação para um estudo sobre Macau, apesar de ainda serem pouco estudadas. No último Encontro Regional Abralic 2007, realizado na FFLCH - USP, e cujo tema foram as "Literaturas, Artes e Saberes", o professor doutor Benjamin Abdala Jr., em pronunciamento de abertura do Encontro, afirmou a necessidade de se pensar as relações ibero-afro-brasileiras como uma possibilidade de resistência comunitária em face dos fluxos crescentes dos processos de globalização. Este trabalho pretende estender a abrangência dessas relações, refletindo sobre a presença portuguesa no Oriente, mais especificamente, sobre deslocamentos de portugueses que envolvem as rotas da África a Macau. Dessa forma, pensamos contribuir para uma reflexão que gira em torno de determinações complexas dos agenciamentos literários.

\section{Migrações e diásporas - rasuras de contornos}

Do século XIX ao XX, a consolidação da soberania sobre territórios ultramarinos tornou-se um dos fundamentos básicos da estratégia política dos países europeus: Portugal, Inglaterra, França, Espanha, Holanda e Alemanha. Entre 1815 e 1914, segundo Edward Said (1990, p. 51), o domínio colonial direto europeu cresceu de uns 35\% para cerca de $85 \%$ de toda a superfície da terra. As relações internacionais tornaram-se bastante complexas, e é nesse contexto que a história de Macau se inscreve, principalmente no âmbito das relações de Portugal e da China com a Grã-Bretanha, Brasil e países da África. A ambigüidade das relações luso-inglesas, por exemplo, em que o termo "aliado" iria, no decorrer do século XIX, transformar-se de "adjuvante" em ódio proclamado pelos portugueses, após o Ultimatum, espelha as cifras voláteis com as quais os países constroem suas nacionalidades econômica e imaginariamente. As nações, como sugere o já clássico estudo de Benedict Anderson (1989), são "comunidades imaginadas", e poderíamos acrescentar: imaginadas em suas fronteiras altamente instáveis perante os fluxos migratórios e diaspóricos. Será que podemos pensar nas relações ibero-afro-brasileiras como um contorno fora e à parte da globalização? Fora e à parte das relações luso-inglesas ou daquelas que envolvem outros espaços de acentuada 
presença portuguesa? Ou de que forma poderíamos imaginar esse contorno dentro da globalização, constituindo-se como uma "resistência"? Apenas quero apontar para as dificuldades de se definir um contorno qualquer que envolva relações internacionais como ponto de partida para a enunciação de uma "resistência" à globalização.

Por um lado, o contorno ibero-afro-brasileiro, ou ainda outro, como é o caso do contorno lusófono, evidencia identidades culturais que, nos processos hegemônicos, foram desprestigiadas na constituição literária do cânone, mas por outro, estabiliza valores mais ou menos fixos de miscigenações nas constituições identitárias, em detrimento de outras relações culturais que afirmam o caráter continuamente híbrido da identidade cultural e as disjunções nas relações de poder. Além disso, as ações em torno desses contornos empenham-se numa cooperação cultural que esbarra em defasagens econômicas, em gestões de estratégias internacionais muitas vezes descoordenadas, em restrições de recursos e, quase sempre, num inventário de ignorâncias. Difícil determinação essa, a de uma nova fundação.

Parece-nos que o desenraizamento de escritores de língua portuguesa disponibiliza efetivas interações que precisam ser registradas, mesmo que os registros ultrapassem as condições para se pensar em "comunidades".

No geral, às comunidades portuguesas espalhadas pelo mundo, é associado o termo "diáspora". Esse termo, exemplar da história do povo judeu, segundo a narrativa bíblica, implica os sentidos de povo escolhido, escravidão, sofrimento e busca de redenção com a qual boa parte das comunidades afro-descendentes, do século XX, se identifica (cf. HALL, 2003: 28-29). Mas, ao contrário do exemplo, não foram os portugueses capturados para serem escravos em outras terras, mas foram, sim, senhores nas redes que o império formou. Lógico que essa é apenas uma face da moeda. A história das migrações portuguesas não se resume àquelas emigrações cuja prática correspondeu a uma etnicidade dominante nos espaços coloniais.

Dentre as formulações que buscam um entendimento dos processos que constituem a sociedade portuguesa, Boaventura de Sousa Santos alega que a sua formação "caracteriza-se por articulações complexas entre práticas sociais e universos simbólicos discrepantes, que permitem a construção social, tanto de representações do centro, como de representações da periferia" (SOUSA SANTOS, 1994: 54). Para ele, o elemento básico da existência coletiva portu- 
guesa é o fato de Portugal ter sido "simultaneamente o centro de um grande império colonial e a periferia da Europa" (ibid., p. 59). Isso mostra a ambivalência da existência coletiva do português e aponta para formas nada homogêneas da sua fixação e dos seus modos de ser nos espaços para os quais se deslocou. Além de o império português não ter sido espacialmente contíguo, as emigrações econômicas, fruto da sua condição européia periférica, sobrepuseram-se, ao longo dos anos, aos vínculos históricos coloniais. Por isso, as relações entre os espaços em que a cultura portuguesa se desenvolveu precisam ser olhadas em suas diferenciadas histórias e constituições imaginárias.

\section{Macau - demarcações políticas e literárias}

Em 13 de abril de 1987, Portugal e a República Popular da China assinaram em Beijing a Declaração Conjunta, na qual ficou definido o processo e a data da transferência da administração do território. Portugal assumiu a responsabilidade de governar Macau até 19 de dezembro de 1999, promovendo o desenvolvimento econômico e preservando a estabilidade social. Por sua vez, a República Popular da China aceitou que o território se tornasse a Região Administrativa Especial de Macau (RAEM), em conformidade com o princípio "um país, dois sistemas", fórmula que busca conjugar a unidade da China comunista aos modos do desenvolvimento econômico capitalista. Em 20 de dezembro de 1999, a soberania administrativa de Macau era passada de Portugal à República Popular da China. Foi assim que terminou o fim do império português. Bem diferente do início do fim, no século XX, quando as tropas de Nehru invadiram Goa, expulsando de lá os portugueses, ou das terríveis guerras coloniais na África, dos anos 60 e 70, em que as independências foram conquistadas por força, ou, ainda, da situação de Timor, que, invadido pela Indonésia, só alcançaria sua autodeterminação em 1998.

A situação de Macau foi resolvida diplomaticamente. Em 1972, a República Popular da China enviava ao Comitê Especial das Nações Unidas para a Descolonização uma declaração em que afirmava serem as questões de Hong Kong e Macau problemas do âmbito da soberania da China, não pertencendo à chamada "descolonização", pelo fato de resultarem de tratados desiguais impostos pelo imperialismo ocidental à China. 
Aos poucos, Portugal e a República Popular da China convergiam para uma determinação comum acerca do futuro de Macau. Contudo, a política aplicada em Macau, de forma consensual entre Portugal e a China, resvalou em posições múltiplas discordantes, que se situaram criticamente em relação às determinações impostas para a condução do futuro do território. Sousa Santos e Gomes (1998, p. 9) observaram que houve uma duplicidade estrutural presente no projeto político do período de transição, por conta de o reconhecimento formal da autonomia de Macau ter convivido contraditoriamente com uma forte tutela exercida pela República Popular da China e pelo poder central da República Portuguesa. Nesse sentido, segundo os autores, a linha de conduta que atravessou o período de transição teria sido caracterizada pela convergência de discursos oficiais sobre as relações luso-chinesas, liderança das negociações pela parte chinesa e "amorfismo da sociedade de Macau", com ausência de lideranças locais devido ao défice democrático a que essa sociedade se sujeitou. A crítica dos autores já era evidenciada nos versos do escritor macaense José dos Santos Ferreira: "Não queremos que vás / Nem tu própria quererás ir... / Mas quem somos nós / Neste mundo de gente poderosa / O que somos nós / Neste mar de ondas agrestes?” (FERREIRA, 1996: 249).

Macau não teve a sua independência, e teve o seu espaço transformado numa região especial que atravessou uma reformulação total da identificação do macaense em relação aos tradicionais vetores que definiam o seu projeto étnico, ou seja, a associação com a língua portuguesa, a miscigenação entre sangue europeu e asiático e/ou a identificação com o cristianismo. Em fins da década de 1960, com a introdução da televisão em cantonês, afirmase progressivamente a mudança das formas de socialização da comunidade, privilegiando-se o cantonês como língua de interação. As antigas estratégias associadas ao contexto matrimonial também foram deixando de funcionar, por conta da tendência que se manifestou, durante os anos 1980, de os casamentos se fazerem fora da comunidade lusófona (cf. PINA CABRAL e LOURENÇO, 1993).

Os macaenses foram deixando de se apresentar como promotores de um projeto colonial e foram passando a legitimar a sua presença em virtude de uma contribuição histórica de diferenciação que Macau traria para a própria China. Afinal, a constituição cultural híbrida do território é o fundamento que garantiu ao território ser considerado "especial". 
Juntamente às transformações políticas e dos projetos étnicos, ocorreu uma alteração profunda dos modos de recepção da produção literária dos escritores macaenses enquadrados na lusofonia. A recepção de textos de autores macaenses, como José dos Santos Ferreira, Luís Gonzaga Gomes, Deolinda da Conceição e Henrique de Senna Fernandes, passou a ser atualizada em função de uma acumulação de significados que corresponde à tradição do passado de uma dentre as várias etnias que compõem o território, deslocando uma perspectiva que abrangia esses textos como a representação de uma força cultural dominante e colonial. Dessa forma, a memória coletiva dos macaenses pôde, nos anos de transição, ser legitimada em suas particularidades - no patoá, por exemplo, hoje patrimônio da UNESCO -, por se enquadrar numa situação caracterizada pelo multiculturalismo, o que reforça a condição particular do território.

Entre os programas dos anos de transição, entre 1987 e 1999, houve um incremento significativo das estratégias educacionais e culturais, a fim de se proteger, em certa medida, o patrimônio cultural português. Muitas obras foram reeditadas e editadas por institutos e fundações, com o fim de evidenciar a cultura e as artes de Macau. No mar de empreendimentos e acontecimentos que transcorreram, nesses anos, antigos residentes portugueses que haviam partido, portugueses que haviam nascido em outros pontos do império e portugueses do continente transferiram-se para a região de Macau. Esses deslocamentos trazem uma complexidade ainda maior às considerações sobre a literatura de Macau.

Ana Paula Laborinho (1999), ao comentar o texto "Literatura Chinesa de Macau entre os anos 80 e o princípio dos anos 90”, de Cheng Wai Ming, mostra as dificuldades de uma definição da literatura de Macau. Entre tantas, está a dificuldade de restringir a literatura de Macau àqueles que nasceram no território. Muito da literatura produzida em Macau, tanto em expressão portuguesa quanto chinesa, deve-se a autores que nasceram em algum outro lugar. Isso se deve principalmente ao fato de a região ter tido historicamente uma vocação de "passagem". Laborinho comenta ainda um artigo de outro autor chinês, Weng Chong, cujo título é "Sobre a definição da literatura macaense", em que parece restringir a caracterização macaense a sua função adjetiva, algo que significaria "literatura sobre Macau" (CHONG apud LABORINHO, 1999: 20). Parece que ainda temos um longo caminho a percor- 
rer na caracterização e identificação de uma literatura de Macau. De qualquer modo, considerando que de fato o critério de nascimento no território seja insuficiente, passaremos a percorrer algumas obras que surgiram das rotas de Portugal à África a Macau.

\section{De Portugal à África a Macau - rotas poéticas}

Das rotas africanas surgiram, na produção literária de Macau, nos anos de transição, modulações de vozes e ritmos que procuraram marcar as transformações espaciais. O moçambicano João Rui Azeredo, historiador, que se transferiu para Macau para lecionar, publicou, em 1992, Poemacau, uma pequena obra poética, que expressa o fascínio pelas ruas da cidade numa inquietante ausência de domínio do tempo.

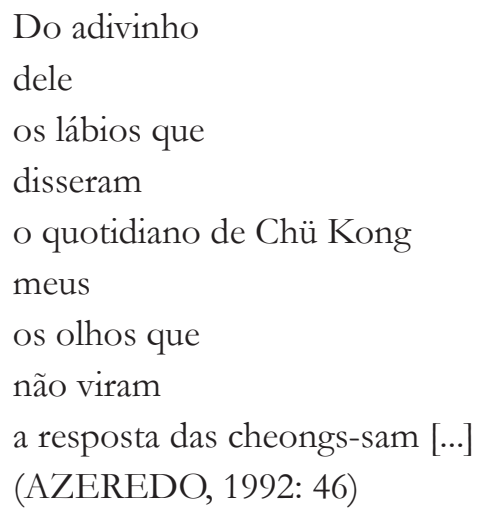

A impossibilidade de adivinhar o tempo reorganiza o registro da poesia de acordo com a relação da topografia no instante. $O$ poeta produz imagens instantâneas que, em sucessão, vão revelando a visibilidade espacial de monumentos, ruas, pontes e portos. No seu testemunho, a observação da cidade pelas marcas de ontem reverencia a construção da memória - "labaredas consumiram-te os ossos / resistiu na tua face / o olhar que desafia a história / por ele / espreito / agora / [...]” (ibid., p. 29). As ruínas do milênio são as sobras do passado e designam o momento contemporâneo de Macau que, em "Contagem regressiva" (p. 30), torna-se a vertiginosa agonia da perda que a 
transferência implicou, causando uma inversão temporal em que a contagem do tempo significa sempre menos. O "eu" lírico ancora em si mesmo a enunciação de um fluxo de esperanças: "Interior e exterior / portos são tráficos de esperanças / e portos seremos também” (p. 31). Na modulação da voz, o sujeito se expressa como local de passagem, de chegadas e de partidas.

Uma rota poética de maior fôlego, que percorre os caminhos de África a Macau, é a do angolano Jorge Arrimar. Na década de 1970, fundou o Grupo Cultura da Huíla (Grucuhuila), sendo responsável também por um suplemento literário no Jornal da Huila. Nesse jornal, foram publicados os seus primeiros poemas, além de trabalhos etnográficos. Seu primeiro livro de poemas, Ovatylongo, foi publicado em 1975 e contou com prefácio do etnólogo Carlos Estermann. De lá para cá, publicou mais sete livros, que acompanharam os seus deslocamentos por Portugal, Açores e Macau. Chegou a Macau em 1985, indo trabalhar primeiramente no Arquivo Histórico e, mais tarde, na direção da Biblioteca Nacional. Sua obra não é incluída nos dicionários nem nas histórias da literatura portuguesa, mas foi integrada ao Dicionário de Autores de Literaturas Africanas de Lingua Portuguesa, de Aldónio Gomes e Fernanda Cavacas, publicado pela editora Caminho, em 1997, e no quarto volume da coletânea De longe à China - Macau na historiografia e na literatura portuguesas, de Carlos Pinto Santos e Orlando Neves, publicado pelo Instituto Cultural de Macau, em 1996. O mesmo acontecerá ao poeta português Alberto Estima de Oliveira, de quem falaremos um pouco mais adiante.

$\mathrm{Na}$ introdução do dicionário de autores de literaturas africanas, os autores trazem as questões "Que autores incluir?" e "Quem é autor?" para tentar justificar os critérios de sua seleção. Primeiro, ponderam sobre a realidade objetiva africana, mostrando as dificuldades de se publicar naqueles países. Essa é a justificativa para o fato de incluírem autores com pelo menos uma obra publicada autonomamente. Depois, ao esclarecer os objetivos do dicionário: "proporcionar a potenciais leitores - leitores comuns, professores, escritores, críticos - dados e referências sobre os escritores de língua portuguesa de algum modo ligados à África [...]”, fica claro que esse critério corresponde a um limite não-delimitável, a uma fronteira nada rígida, tão evasiva quanto aquela que aparece na busca de uma delimitação da literatura de Macau. Estamos diante de uma dificuldade que parece revelar-se como recusa aos padrões comumente aceitos de delimitação dos cânones literários. Apesar de os critérios 
não serem tão objetivos como a necessidade parece comandar e de abrirem as portas para enormes discussões, não poderíamos assistir a essa dificuldade como uma inscrição da diferença irrecusável, daquela margem necessária a um estar presente, e de um outro modo? E, talvez, ousaria perguntar, não estaria em um critério "semi-objetivo" justamente a possibilidade de uma renovação profunda dos cânones literários inscritos sob o signo nacional, inclusive daqueles que costumamos nomear "ocidentais"? Ainda bem que podemos falar em dissensos, gerar tensão nos consensos e mudar, verbalizar a muda em transformação viva. Ou não acreditamos que na margem já esteja o "para lá” do limite?

Trago da já vasta obra de Jorge Arrimar (1997) a ponta de um único poema, inserido em um livro, cuja idéia bastante original de publicar a sua poesia conjuntamente com a de Yao Jingming (Manuel Yao), com as autorias reveladas apenas no índice final, revela a possibilidade de confluências, palavra título do livro, entre histórias de vidas tão diferentes.

\author{
Margem \\ Esta é a margem \\ onde os limites \\ se reconhecem \\ $[\ldots]$
}

(ARRIMAR e YAO, 1997: 143)

Quando “os limites se reconhecem”, surge espontaneamente a possibilidade de os afetos harmonizarem as vozes. Jorge Arrimar e Yao Jingming caminham juntos em Confluências (1997) e também na Antologia de poesia de Macau (1999). E aproveito para perguntar: Yao Jingming, chinês, nascido em Beijing, licenciado em Língua e Cultura Portuguesa, com vários ensaios escritos sobre a moderna poesia portuguesa e escrevendo livros de poesia em português, poderia ser incluído em qual literatura?

Ainda nas rotas de África a Macau, viaja a poesia do português Alberto Estima de Oliveira, nascido em Lisboa. O poeta viveu em Benguela e Lobito, em Angola. Teve a sua poesia publicada nos cadernos Vector II e III (Huambo, Nova Lisboa) e na Antologia Kuzuela III, primeira Antologia de Poesia Africana de Expressão Portuguesa (Luanda), coligida por David Mestre. Depois 
de um breve regresso a Portugal, em 1975, fixa-se na Guiné-Bissau, durante três anos, a partir de 1977. Depois, foi para Macau, em 1982, onde residiu até 2001. Atualmente vive em Lisboa. Como Jorge Arrimar, seu nome é referido no Dicionário de autores de literaturas africanas de língua portuguesa (1997) e na coletânea de Orlando Neves e Carlos Pinto Santos. Curiosamente, apenas em 2003, um livro seu saiu publicado em Portugal, o Mesopotâmia - espaço que criei, pela editora Aríon, apesar de em 1999 ter-lhe sido atribuído o Grande Prêmio Internacional de Poesia no International Festival "Curtea de Arges Poetry Nights" e de ter sua poesia traduzida em outras línguas.

A maior parte da poesia de Estima de Oliveira foi publicada em Macau, fruto da sua vivência de 19 anos no território. O livro Mesopotâmia - espaço que criei, publicado em Portugal, é uma antologia, selecionada pelo próprio autor, das obras Infraestruturas (1987), O diálogo do silêncio (1988), O rosto (1990), O corpo (com)sentido (1993), O esqueleto do tempo (1995), Estrutura I: o sentir (1996), mais um grupo de poemas inéditos.

Poesia nascida da inquietação, com intensa percepção da convulsão do tempo e que legitima o silêncio co-extensivo ao sujeito desejante, ela parece precisar as dificuldades da construção de um lugar para habitar.

como é tão longo

este caminho

que leva ao sol

(ESTIMA DE OLIVEIRA, 2003: 128)

Apesar de se lançar ao inacabado inventário das culturas do mundo, ao jogo perigoso em direção ao outro e a desconhecidas conjunções do Ocidente e do Oriente, o olhar situa o sujeito entre resíduos e rejeitos do espaço, mas firme na estrada dos registros mínimos de luzes e de águas, naquele ponto universal tão próximo ao de outras poesias de expressão portuguesa, como as de Sophia de Melo Breyner ou a de Eugénio de Andrade.

$\mathrm{Na}$ realidade das poesias dessas rotas entre Portugal, África e Macau, legitimam-se vozes mescladas de hibridismos que nem sempre encontram abrigo nas editoras ou na crítica, mas que intensificam a força vital da palavra poética de expressão portuguesa. Através delas, a opacidade do mundo transmuta-se em palavras de densidades corpóreas e/ou substantivas, resvalando sempre 
em efetivas trocas culturais. É urgente que elas circulem, mesmo que sobrevoando por sobre os contornos de um determinado pertencimento cultural.

\section{Referências Bibliográficas}

ANDERSON, Benedict. Nação e consciência nacional. São Paulo: Ática, 1989.

ARRIMAR, Jorge; Manuel Yao. Confluências. Macau: Folha de Lótus, 1997.

; JINGMING, Yao. Antologia de poetas de Macau. Macau: Instituto Camões, Instituto Cultural de Macau e Instituto Português do Oriente, 1999.

AZEREDO, João Rui. Poemacau. Macau: Livros do Oriente - Instituto Português do Oriente, 1992.

ESTIMA DE OLIVEIRA, Alberto. Mesopotâmia - espaço que criei. Lisboa: Aríon, 2003.

FERREIRA, José dos Santos. Obras completas de Adé. v. IV. Macau: Instituto Cultural de Macau, 1998.

GOMES, Aldónio; CAVACAS, Fernanda. Dicionário de autores de literaturas africanas de língua portuguesa. Lisboa: Caminho, 1997.

HALL, Stuart. Da diáspora - identidades e mediações culturais. Org. Liv Sovik. Belo Horizonte: UFMG, 2003.

LABORINHO, Ana Paula. Por uma literatura de Macau. In: ARRIMAR, Jorge; JINGMING, Yao (sel. e org.). Antologia de poetas de Macau. Macau: Instituto Camões, Instituto Cultural de Macau, Instituto Português do Oriente, 1999.

PINA CABRAL, João de; LOURENÇO, Nelson. Em terra de tufões. Dinâmicas da etnicidade macaense. Macau: Instituto Cultural de Macau, 1993.

SAÏD, Edward W. Orientalismo. O Oriente como invenção do Ocidente. São Paulo: Companhia das Letras, 1990.

SANTOS, Carlos Pinto; NEVES, Orlando. De longe à China - Macau na historiografia e na literatura portuguesas. v. IV. Macau: Instituto Cultural de Macau, 1996.

SOUSA SANTOS, Boaventura. Pela mão de Alice. O social e o político na pós-modernidade. Porto: Afrontamento, 1994.

; GOMES, Conceição. Macau: o pequeníssimo dragão. Porto: Afrontamento, 1998. 